University of Nebraska - Lincoln

DigitalCommons@University of Nebraska - Lincoln

Management Department Faculty Publications

Management Department

$6-2012$

\title{
Workplace Spirituality, Meditation, and Work Performance
}

\author{
Pawinee Petchsawanga \\ University of the Thai Chamber of Commerce, Thailand, ppetchsawang@yahoo.com \\ Dennis Duchon \\ University of Nebraska-Lincoln, dduchon2@unl.edu
}

Follow this and additional works at: https://digitalcommons.unl.edu/managementfacpub

Part of the Management Sciences and Quantitative Methods Commons

Petchsawanga, Pawinee and Duchon, Dennis, "Workplace Spirituality, Meditation, and Work Performance" (2012). Management Department Faculty Publications. 92.

https://digitalcommons.unl.edu/managementfacpub/92

This Article is brought to you for free and open access by the Management Department at DigitalCommons@University of Nebraska - Lincoln. It has been accepted for inclusion in Management Department Faculty Publications by an authorized administrator of DigitalCommons@University of Nebraska - Lincoln. 


\title{
Workplace Spirituality, Meditation, and Work Performance
}

\author{
Pawinee Petchsawanga, Department of Human Resource Management, School of Business, \\ University of the Thai Chamber of Commerce, Thailand
}

Dennis Duchon, Department of Management, University of Nebraska-Lincoln, Lincoln, NE, USA

Corresponding author - P. Petchsawanga, email ppetchsawang@yahoo.com

\begin{abstract}
This paper reports two studies that examine how an organization might enable more productive work practices by encouraging the expression of its employees' spiritual selves in an eastern context. Study 1 shows that people who regularly practice meditation have higher workplace spirituality scores than people who do not regularly practice meditation. Study 2 reports a quasi-experimental study in which people practiced insight meditation. The data did not reveal a direct effect for the meditation, however spirituality does relate to work performance. Moreover, the practice of meditation is also found to partially mediate the relationship between workplace spirituality and work performance.
\end{abstract}

Keywords: workplace spirituality, meditation, work performance, human resource, organizational behavior

Transformation can begin in the workplace when organizations open themselves to the cultivation of their own employees' spirituality. This would mean addressing employees as whole human beings in terms of their physical, mental, emotional, and spiritual needs (Dehler and Welsh 2003). Lifting up the whole person in the workplace should not be seen entirely as an altruistic act. Research has demonstrated that by addressing the spiritual side of human experience organizations help reduce stress, enhance creativity, and improve problem solving (Tischler et al. 2002). By focusing on the spiritual qualities of meaningfulness and joy at work, organizations have found increased job satisfaction (Harung et al. 1996), enhanced job involvement, organizational identification, and work rewards satisfaction (Kolodinsky et al. 2008), greater honesty, trust, and commitment (Krishnakumar and Neck 2002), and even improved work performance (Duchon and Plowman 2005).

Spirituality at work is not a fringe idea. In fact, spirituality at work addresses human activities such as personal development, learning, compassion, and searching 
for meaning or higher purpose (Gull and Doh 2004). Successful organizations such as Hewlett-Packard, Tom's of Maine, Ford Motor Company (Burack 1999), the World Bank (Laabs 1995), AT\&T, Chase Manhattan Bank, DuPont, and Apple Computer (Cavanagh 1999), have created programs to bring spirituality to the workplace. For example, AT\&T sends middle managers to three-day development programs that help the participants better understand themselves and better listen to their subordinates (Cavanagh 1999). The pursuit of self-knowledge and an ability to "listen" rather than control are central features in many spiritual quests. Hewlett-Packard builds spirituality in the workplace through a company philosophy that emphasizes the values of trust and mutual respect, which in tum are believed to contribute to cooperation and sharing a sense of purpose (Burack 1999).

This paper reports two studies that examine how an organization might enable more productive work practices by encouraging the expression of its employees' spiritual selves in an eastern (i.e. non-Western) context. Study 1 shows that people who regularly practice meditation have higher scores on a measure of spirituality in the workplace than people who do not regularly practice meditation. Study 2 reports a quasi-experimental field study in which people are trained in the practice of insight meditation. The practice of meditation, measures of spirituality, and measures of work performance are then examined, and while there are significant relationships among the three variables, the practice of meditation is also found to partially mediate the relationship between workplace spirituality and work performance.

\section{Spirituality at work}

Interest in spirituality as a scholarly topic has grown in recent years, possibly as a result of the confluence of disparate events. For example, Cacioppe (2000) has argued that the modem world is plagued by social, economic, and environmental problems that are the result of human greed and a lack of love and compassion. He contends that these large-scale problems have triggered in humankind a renewed search for harmony and peace, a search that is essentially a spiritual journey. Biberman and Whitty (1997) have gone so far as to claim that organizational studies have undergone a fundamental shift from a mechanistic paradigm that values rationality and science to a spiritual paradigm that values consciousness and understanding. Such a shift enables an emphasis on issues such as team work, trust, creativity, and openness to change as approaches to dealing with the disruptions caused by the drive toward globalization (e.g. downsizing, outsourcing, etc.) by keeping businesses thriving in a changing world.

The spiritual paradigm essentially recognizes that people work not only with their hands, but also their hearts or spirit (Ashmos and Duchon 2000). It is when people work with a committed spirit they can find a kind of meaning and purpose, a kind of fulfillment which means the workplace can be a place where people can express their whole or entire selves. Thus, enabling the expression of human experience at its 
deepest, most spiritual level may not only reduce stress, conflict, and absenteeism, but also enhance work performance (Krahnke et al. 2003), employee well-being, and quality of life (Karakas 20 I 0).

Although no widely accepted definition of workplace spirituality exists (Kinjerski and Skrypnek 2004), there seems to be an emerging consensus that spirituality is a multifaceted construct that is about finding a connection to something meaningful that transcends our ordinary lives (cf. Mitroff and Denton 1999, Dehler and Welsh 2003, Tepper, 2003, George et al. 2004). Note, that the workplace is seen as an arena where spirituality can be found and expressed (cf. Ashmos and Duchon 2000, Cacioppe 2000, Giacalone and Jurkiewicz 2003, Milliman et al. 2003, George et al. 2004). The idea is that when people fully engage their work with a sense of purpose they approach expressing their complete selves, including their spiritual selves. Workplace spirituality can thus be interpreted to be meaningful at both the individual and the organizational levels of analysis (Kolodinsky et al. 2008, Pawar 2008). At the individual level, spirituality can be seen as an affective and cognitive experience: an employee feels and believes in a spiritual connection to work and the work place. At the organizational level, spirituality can be seen as a reflection of spiritual values that is part of the organization's culture and is thus used to inform behavior, decision-making, and resource allocation (Kolodinsky et al. 2008). Moreover, Pawar (2009) suggests that workplace spirituality can be encouraged at both levels. At the individual level people might participate in spiritual development programs (e.g. learning meditation). The organization itself can use spiritual values to modify organizational planning and strategy making, HRM practices (hiring, training, development, and evaluation), and, as noted above, the culture that provides a context for daily life.

Finally, although spirituality is often associated with the practice of religion, there is wide agreement that it is distinct from the practice of religion. A distinction is important because the workplace is considered a secular environment, particularly in western societies (Mitroff and Denton 1999, Cacioppe 2000, Hill and Smith 2003, Ashar and Lane-Maher 2004). By integrating the multiple meanings of workplace spirituality, this paper defines it as having compassion toward others, experiencing a mindful inner consciousness in the pursuit of meaningful work that enables transcendence (Petchsawang and Duchon 2008). Note that while this definition is based in the mostly western-focused literature devoted to spirituality at work, it also extends these definitions by allowing for an eastern sensibility toward spirituality.

\section{Study 1: The practice of meditation and the measure of workplace spirituality}

Western approaches to spirituality have generally focused on the existence and power of each person's inner being; that is, spirituality is a disposition that can vary among individuals. Questionnaire measures have been developed to cap- 
ture this disposition (cf. Ashmos and Duchon 2000, Milliman et al. 2003, Delaney 2005, Kinjerski and Skrypnek 2006). Study 1 developed a questionnaire measure of spirituality, but also connected the disposition toward spirituality with a behavioral indicator of spirituality commonly found in eastern, Buddhist-centric cultures: meditation.

Both Study 1 and Study 2 were conducted at the same large Thai company (see below). Major companies in Thailand conduct programs that are aimed at developing the spiritual well-being of their employees. Such programs are seen as normal business practice because Thailand's culture has, for 2500 years, honored the Philosophy of Buddhism. Buddhism is a set of teachings aimed at helping humans experience reality, and because it does not account for a personal God, nor does it espouse theology or dogma, it is not a religion in the sense that Christianity and Islam are religions. Rather, Buddhism expresses a set of principles intended to help people steer a middle course in their daily lives. Buddhism is deeply spiritual, however, in that the philosophy intends to develop mindfulness, concentration, compassion, and wisdom in its followers. These spiritual qualities are developed through the practice of meditation, and developing these spiritual qualities is believed to contribute to harmony and balance in life. It is important to note that Buddhist meditation 's goal of "mindfulness" has a meaning different from the way mindfulness is usually operationalized in western research aimed at better understanding cognition's role in decision-making. In Buddhist mediation, mindfulness refers to a kind of concentration that can lead to penetrative insight or wisdom. In contrast, mindfulness in the western perspective refers to the cognitive processes involved in paying attention to external events (Weick and Putnam 2006).

While the practice of meditation has been empirically connected to therapeutic outcomes in the fields of nursing and health care (cf. Thompson and Waltz 2007), this current research examines spirituality and the practice of meditation in a work context in Thailand, a country whose culture has long accepted meditative practice as a normal part of everyday life.

Essentially, there are two types of Buddhist meditation, both of which aim at training and purifying the mind: (I) tranquility meditation and (2) insight meditation (Payutto 2002). Tranquility meditation aims to develop concentration. From a western perspective, this approach to meditation is widely known as a relaxation or stress-reduction technique. In contrast, insight meditation aims to achieve wisdom and "see the truth nature of life and the world" (Payutto 2002). Insight meditation is better suited to a study of spirituality at work because by focusing on the moment, a person can achieve a focused awareness or mindfulness of him/herself, his/her thoughts and feelings, that in turn enables a more complete (and appropriate) engagement with everyday experience (Pra Rajaprommajarn 2004). Payutto (2002) has noted that when people face problems, they may use tranquility meditation to calm their minds and acquire happiness. Indeed, they could escape from reality and problems while practicing the meditation, but the problems still remain. In other words, practicing tranquility mediation does not directly assist problem solving, but practic- 
ing insight meditation does. The mindfulness acquired by practicing insight meditation enables insight or wisdom - see the truth of nature (which is the optimal benefit of Buddhist meditation) and by seeing truth be able to solve problems. Solving problems has direct, important consequences in the workplace and so is a more appropriate meditation form to examine in a work context (see also Tischler et al. 2002). Also, insight meditation aims at developing focus and concentration on the present. These are mental skills that could plausibly be applied in the workplace such that focus and concentration might be associated with improved task performance (Weick and Putnam 2006).

There has been some effort to connect meditation and work outcomes, but these efforts have been limited, and have not focused on insight meditation. For example, Schmidt-Wilk (2003) reported that 10 members of a Swedish top management team who practiced transcendental meditation claimed to have developed a kind of developmental maturity that allowed them to implement a total quality management program. Similarly, McCollum (1999) explored relationships between leadership development and self-development. Study participants who practiced transcendental meditation claimed to be more effective at work.

Study 1 developed a questionnaire measure for workplace spirituality and examined the relationship between spirituality scores and frequency of meditation. Items for the questionnaire were adapted from previously published measures (cf. Ashmos and Duchon 2000, Brown and Ryan 2003, Kinjerski and Skrypnek 2004, Delaney 2005, Delgado 2005) and address the four factors noted in the definition above: compassion (e.g. I am aware of my coworkers' needs), mindfulness (e.g. I find myself working without paying attention, reversed), meaning at work (e.g. My spirit is energized by my work), and transcendence (e.g. At times I experience moments at work where everything is blissful). The questionnaire was developed in English, then translated into Thai and back-translated into English according to procedures recommended by Maxwell (1996), Birbili (2000), and Hambleton (2002) to insure both text agreement and conceptual equivalence. Informants indicated the extent to which they agreed with each item on a Likert-type scale where $1=$ strongly disagree and $5=$ strongly agree. Full and complete details about the questionnaire's development can be found in Petchsawang and Duchon (2008).

\section{Procedure and results}

The questionnaire was randomly administered to 250 employees of a large (3800 employees) food and baking company in Thailand, none of whom subsequently participated in subsequent data collection. Some 206 questionnaires were returned with complete data ( $82.4 \%$ response rate). The informants (65 males, 141 females) were, on average between 21 and 30 years of age and had been working for the company 5.8 years. The informants, on average, had earned a high school diploma. The informants can be seen as typical of employees working in the food industry in Thailand. 
These data were refined through the application of confirmatory factor analysis $\left(\chi^{2}\right.$ $=312.575, \mathrm{df}=201, p=.00, \mathrm{CFI}=.92$, and RMSEA $=.05)$. Workplace spirituality scores are represented by the mean of 22 items, four items assessing compassion, six items assessing mindfulness, seven assessing meaningful work, and five assessing transcendence. Correlations between each item and its underlying dimension ranged from .34 to .81 and the $r^{2}$ from .12 to .71 , thus providing evidence of adequate convergent validity. Cronbach $\alpha$ for the entire scale is .85. (see Table 1) (Petchsawang and Duchon 2008).

In addition to routine demographic data, the questionnaire also posed the following question: "Do you practice meditation?" Informants checked one of four categories: never, once per month, every week, or every day. So few informants checked "every day" that the responses to that category were combined with those for "weekly," thus achieving three balanced categories: never $(n=80)$, seldom (once per month, $n=86$ ), and often (daily or once per week, $n=38$ ).

The mean workplace spirituality score for those who reported they never practice meditation was $3.92(\mathrm{SD}=.42)$, a score of $3.89(\mathrm{SD}=.37$ ) was reported by informants who claimed to meditate seldom, and informants who reported meditating often achieved a score of $4.11(\mathrm{SD}=.33)$. Analysis of variance reveals statistically significant differences across the three levels of meditation practice $(F(2,203)=4.67, P=$ .01). Post hoc Tukey tests show that those who practice meditation often have significantly higher spirituality scores than those who never practice meditation.

Overall, Study 1 connects spiritual practice (frequency of meditation) with a questionnaire measure of workplace spirituality. While such a connection is not surprising, establishing such a connection essentially creates a foundation for Study 2 where individuals are trained in meditation techniques.

\section{Study 2: Meditation training, workplace spirituality, and work performance}

The first study establishes a connection between workplace spirituality scores obtained from a questionnaire and the frequency of meditation, which is seen as a personal expression of one's spiritual self. That is, a questionnaire score is connected to a behavioral indicator of spirituality. Note in Study 1 that informants were asked only if they practiced meditation. They were not asked which kind of meditation they practiced. Study 2 examines the extent to which an insight meditation training program might affect both workplace spirituality scores and work performance. Study 2 also extends Study 1 by examining how frequency of meditation might be related to both spirituality scores and work performance.

\section{Procedure}

Study 2 is a quasi-experimental study - a pretest-posttest with nonequivalent comparison groups design (Campbell and Stanley 1963). Some 30 participants em- 
WORKPLACE SPIRITUALITY, MEDITATION, AND WORK PERFORMANCE

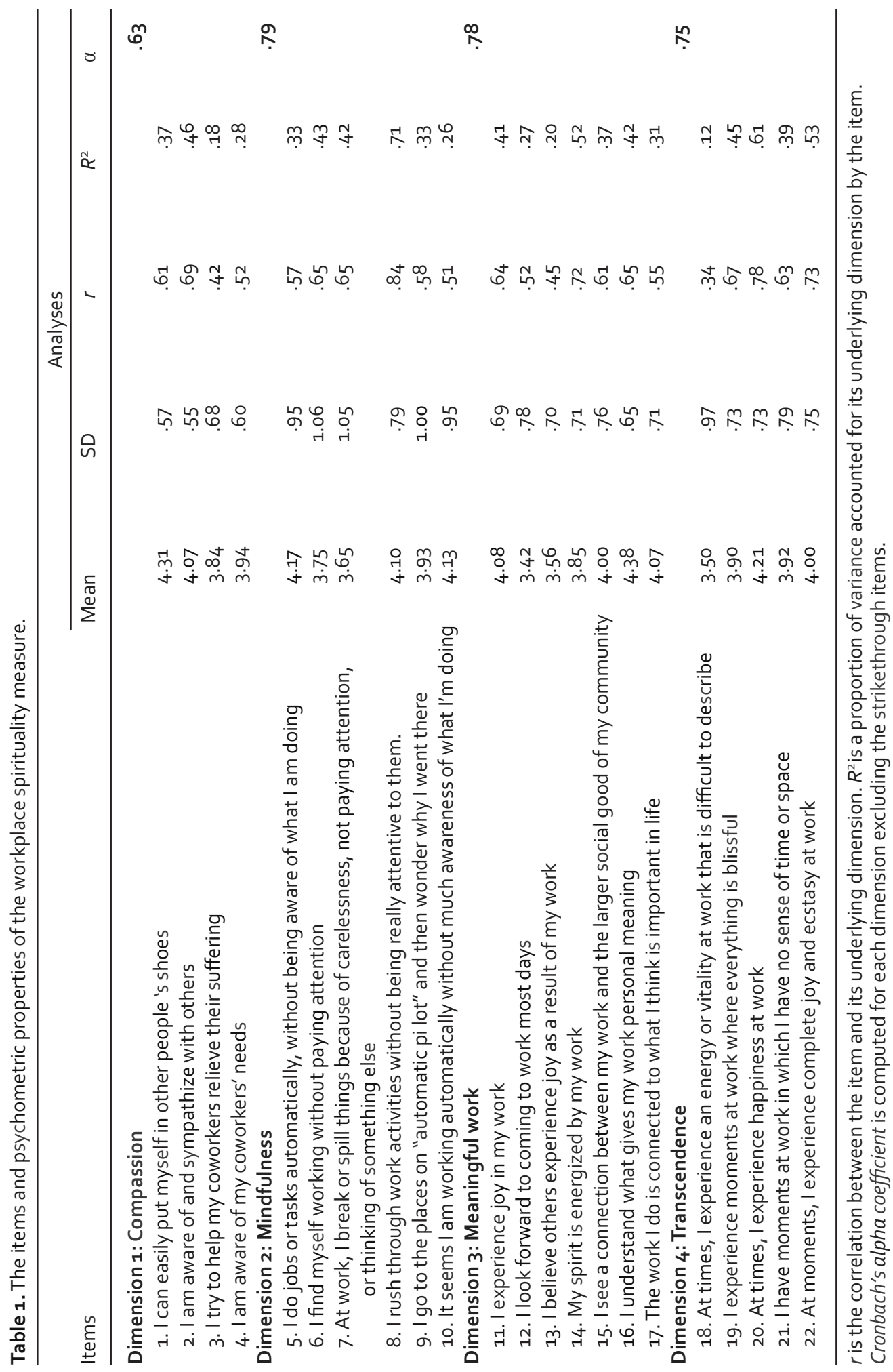


ployed in the same Thai company noted in Study 1 attended a meditation training program. Some 26 of the participants were nominated for the program by their supervisors because they were new employees, while four participants self-nominated. None had previously attended the training program. The 30 members of the comparison group (who also had never attended meditation training) were randomly selected from the same branches and same departments as the participants in the meditation training. From the total of the 60 subjects, some 43 were women $(72 \%)$. Most of the subjects were under 30 years of age, and most of them were not married. Most of the subjects have at least a high school education and most have been working at the company less than two years. Chi-square tests show that the experimental and control groups do not differ in terms of demographics, in terms of gender, age, marital status, religion, education, work experiences, and workplace $(p>.05)$.

The participants in the experimental group completed workplace spirituality questionnaires before the meditation training (T1), one week after the training (T2), and one month after the training (T3). Their work performance was evaluated one month after the meditation training. The participants in the comparison group completed spirituality questionnaires twice, once at T1 and again at T3.

\section{Meditation training}

The meditation training consists of eight days of instruction and practice in insight meditation, and also included learning about the philosophy of Buddhism and group discussion regarding meditation practice. The Thai company has conducted meditation training classes for over 30 years, and training participants are either volunteer or nominated by their supervisors. Training programs are offered six times each year at a company-built facility. Participants are given paid leave time to attend. The company's extensive support for meditation training is a consequence of the CEO's belief that people can benefit greatly from such training. Curiously, however, Study 2 is the first attempt to validate empirically this belief. Details about the training can be obtained from the first author.

\section{Work performance evaluation}

Work performance was assessed by the participants' supervisors, using the company's standard evaluation instrument and procedures. Essentially, supervisors rate their subordinates on five dimensions: (1) work content; (2) work behavior; (3) job specification; (4) discipline; and (5) job knowledge and competency. Table 2 shows that the dimensions are not treated equally; rather, they have different weights. Supervisors assign a rating $(5=$ excellent to $1=$ not satisfactory $)$ to each indicator of a work dimension. For example, the work content dimension has two indicators, quality and quantity of work and both indicators receive a weight of 5 . In contrast, the 
Table 2. Work performance evaluation.

\begin{tabular}{|c|c|c|c|c|c|c|}
\hline \multirow[b]{2}{*}{ Dimensions } & \multirow[b]{2}{*}{$\begin{array}{l}\text { Weight } \\
\text { scale }\end{array}$} & \multicolumn{5}{|c|}{ Rating } \\
\hline & & $\begin{array}{l}\text { Excellent } \\
5\end{array}$ & $\begin{array}{c}\text { Very } \\
\text { good } \\
4\end{array}$ & $\begin{array}{c}\text { Good } \\
3\end{array}$ & $\begin{array}{c}\text { Fair } \\
2\end{array}$ & $\begin{array}{c}\text { Not } \\
\text { satisfactory } \\
1\end{array}$ \\
\hline \multicolumn{7}{|l|}{ 1. Work content } \\
\hline Quality of work & 5 & & & & & \\
\hline $\begin{array}{l}\text { Quantity of work and timeliness } \\
\text { of service (efficiency) }\end{array}$ & 5 & & & & & \\
\hline \multicolumn{7}{|l|}{ 2. Work behavior } \\
\hline Enthusiasm and service mind & 4 & & & & & \\
\hline Compliance with service protocol & 4 & & & & & \\
\hline Cooperation and teamwork & 4 & & & & & \\
\hline Awareness of clean food and safety & 4 & & & & & \\
\hline $\begin{array}{l}\text { Hygiene of equipments, tools, and } \\
\text { work areas }\end{array}$ & 4 & & & & & \\
\hline \multicolumn{7}{|l|}{ 3. Job specification } \\
\hline Hygiene and healthiness & 5 & & & & & \\
\hline Human relation skill & 5 & & & & & \\
\hline Problem solving skill in service & 5 & & & & & \\
\hline \multicolumn{7}{|l|}{ 4. Discipline } \\
\hline $\begin{array}{l}\text { Compliance with supervisor's } \\
\text { command and S\&P policy }\end{array}$ & 5 & & & & & \\
\hline Attendance and discipline record & 5 & & & & & \\
\hline Reporting problems to supervisors & 5 & & & & & \\
\hline \multicolumn{7}{|l|}{ 5. Job knowledge and competency } \\
\hline $\begin{array}{l}\text { Knowledge regarding food and } \\
\text { S\&P products }\end{array}$ & 8 & & & & & \\
\hline Learning and development skill & 5 & & & & & \\
\hline Initiation and creativity & 7 & & & & & \\
\hline
\end{tabular}

work behavior dimension has five indicators (enthusiasm, compliance with service protocol, cooperation and teamwork, awareness of clean food and safety, and hygiene of equipment) and each indicator is assigned a weight of 4 . The indicators, in turn, are rated on a 5-point Likert-type scale that ranges from $5=$ excellent to $1=$ not satisfactory. Each indicator rating score is multiplied by its weight, and the results are summed for each dimension. The total score is averaged.

\section{Mediation training, workplace spirituality, and work performance}

As noted above (Weick and Putnam 2006), meditation practice aims to develop wisdom (i.e. a capacity to be a better problem solver as a result of being able to "see" 
the nature of the problem with greater clarity) and focus and concentration (i.e. a capacity to ignore or filter out distractions). Insight meditation means to develop these mental abilities that enable a person to observe the moment, acknowledge thoughts and feelings without preconception or judgment (mindfulness in the Buddhist sense), and so achieve wisdom (penetrative insight). This enhanced state of awareness can elevate the experience of almost any human activity, including conventional work activity. Weick and Sutcliffe (2006) have noted that when people become more mindful of their work, they develop a capacity for wise action and so perform better. The regular practice of insight meditation ought to enable wise action. Regular practice helps the mind become more powerful in terms of being able to observe distractions and, by observing them, let them go.

Insight meditation also trains the mind to seek a sense of peace and happiness because increased concentration enhances a sense of calm and a sense of energy, both of which can then be used to see things clearly and insightfully. A trained mind can be applied to many circumstances and so there should be carry-over benefits including the potential of performing better work. A calm, disciplined mind, focused on the present, gathering energy is a mind that can better judge the requirements of the moment, make better decisions, and understand more completely the nuances of interpersonal relations. Thus, a trained mind ought to be an asset in the workplace, as it is a mind that can attend to both routine and novel job requirements, can focus on the self or on a group, and, through observation, learn more effectively.

We are not alone in believing that a person whose mind is trained by meditation technique can be a better employee. For example, Marques (2010) argues that the employees who practice the Buddhist meditation will be better team players because they are less likely to inject a selfish agenda. Weick and Sutcliffe (2006) also suggest that by practicing meditation, people will become more creatively aware, become better information processors and so might be more effective in their jobs. The enhanced mental skills associated with practicing meditation can also help employees concentrate better on organizational goals (Weick and Putnam 2006). Finally, being present in the moment (mindfulness) will enhance positive emotions and alleviate negative emotions (Schroevers and Brandsma 2010). Positive emotions at work are believed by some scholars to provide a kind of competitive advantage, and the emerging area of positive organizational behavior is marshaling evidence in support of this belief (cf. Luthans et al. 2007).

In regard to this paper, note that Study 1 presented data that found meditation practice to be associated with a measure of workplace spirituality. That is, meditation practice is associated with an informant's sense of engagement (meaningful work), care and support of coworkers (compassion), task focus and concentration (mindfulness), and enjoyment and energy (transcendence). Thus, it is reasonable to predict that employees with higher spirituality scores will be evaluated by their supervisors as being more disciplined, more enthusiastic, better problem solvers, and more concerned about work quality than those with lower 
spirituality scores because they are more present, more aware, and more focused on the task at hand.

\section{Data analyses}

Table 3 presents a correlation matrix for the study's variables. Similar to Study 1 , the data in Table 3 indicate a relationship between meditation practice and workplace spirituality $(r=.38, p<.01)$ and work performance $(r=.43, p<.01)$. Table 3 also shows a statistically significant relationship between spirituality scores and work performance $(r=.33, p<.01)$.

We then explored further the relationships of workplace spirituality, meditation practice, and work performance. Specifically, we employed a multiple regression approach suggested by Baron and Kenny (1986) to test whether or not meditation practice acted as a mediator for the relationship between workplace spirituality and work performance (see Figure 2). The data reported in Table 4 for step I indicate a direct relationship between work performance and workplace spirituality (path $c$ ) $(\beta=.33, p<.01)$.

Step 2 also indicates a relationship between workplace spirituality and meditation practice (path $a)(\beta=.38, p<.001)$. There is relationship between workplace spirituality and work performance (path $b, r=.36, p<.001$ ), and controlling for this relationship reduces the relationship between workplace spirituality and work performance (path $c^{\prime}$, Figure 1). Therefore, the data indicate that meditation practice partially mediates the relationship of workplace spirituality and work performance.

Beside the above-critical findings, when the data presented in Table 3 are subjected to ANOVA, significant differences across the three levels of meditation practice for both spirituality scores, $F(2,57)=4.89, P=.01$ and work performance, $F(2,57)$ $=6.85, p<.001$ emerge. Follow-up Tukey tests indicate the significance differences are between those who never practice meditation and those who practice meditation often for both spirituality scores and work performance scores.

Table 3. Correlation matrix.

\begin{tabular}{|c|c|c|c|c|c|c|}
\hline Variables & Mean & SD & Training & $\begin{array}{l}\text { Workplace } \\
\text { spirituality }\end{array}$ & $\begin{array}{c}\text { Work } \\
\text { performance }\end{array}$ & $\begin{array}{c}\text { Meditation } \\
\text { practice }\end{array}$ \\
\hline Training & .50 & .50 & 1.00 & .12 & .12 & $.38 * *$ \\
\hline Workplace spirituality & 3.83 & .41 & & 1.00 & $.33^{* *}$ & $.38 * *$ \\
\hline Work performance & 17.05 & 2.82 & & & 1.00 & $.43^{* *}$ \\
\hline Meditation practice & 1.63 & .80 & & & & 1.00 \\
\hline
\end{tabular}

Training is indicated by 1 (experimental group) and o (control group).

$* * p=.01$ 


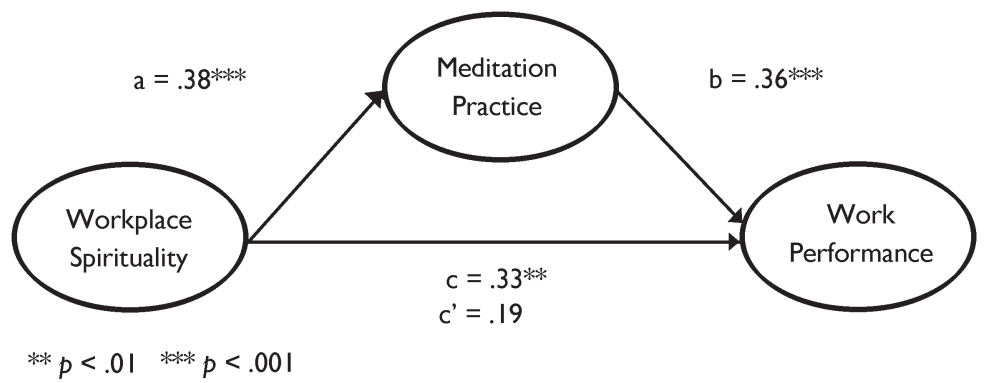

Figure 1. A mediating effect of meditation practice on the relationship of workplace spirituality and work performance.

We then examined the relationship between meditation training and the frequency of meditation practice. A repeated measures ANOVA reveals an interaction such that those study participants who participated in meditation training meditate more frequently than those in the comparison sample $(F(2,58)=18.23, P<.001$ (see Figure 2).

However, the meditation training does not seem to have affected spirituality scores. Mean scores for the workplace spirituality scale for both experimental and

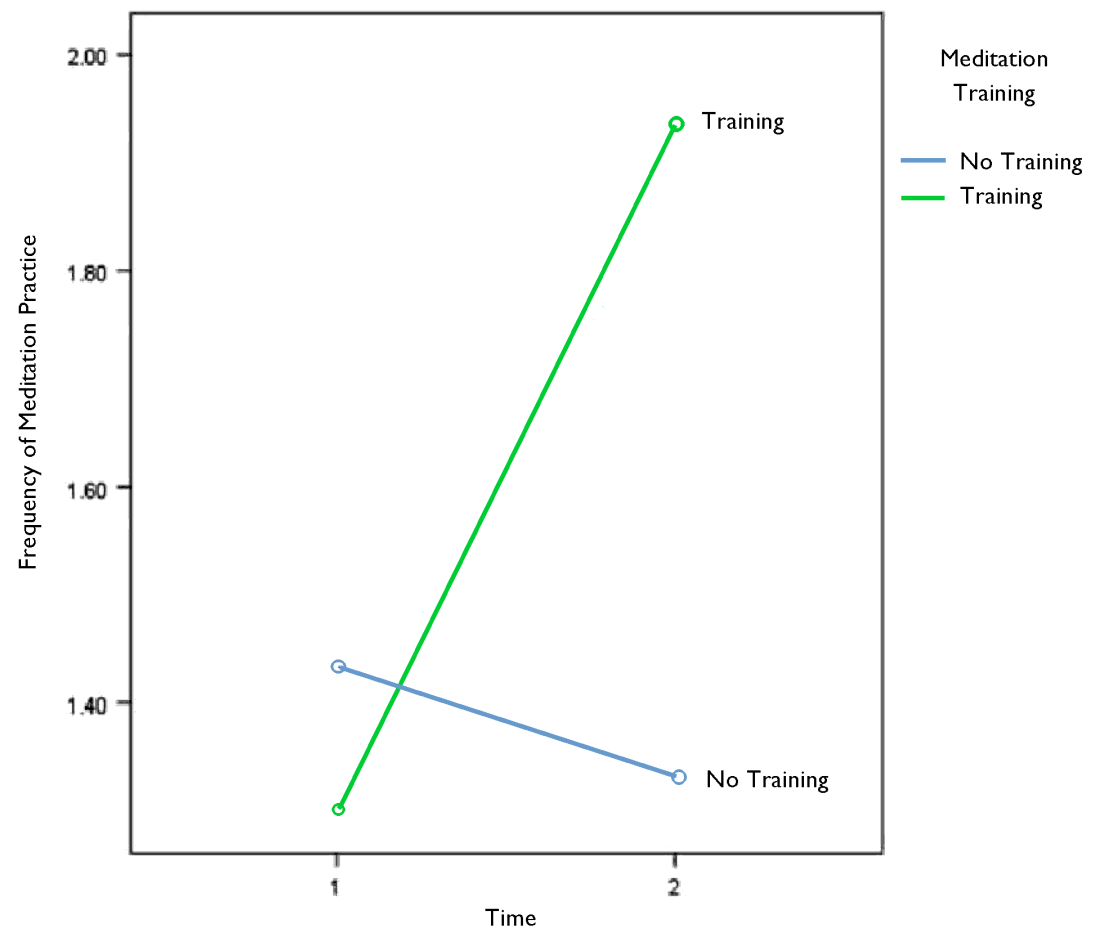

Figure 2. An interaction effect between meditation training and frequency of meditation practice. Frequency of meditation practice scale: $1.00=$ never, $2.00=$ seldom, $3.00=$ often. Time: $1=$ before meditation training, and 2 = after meditation training one month. 


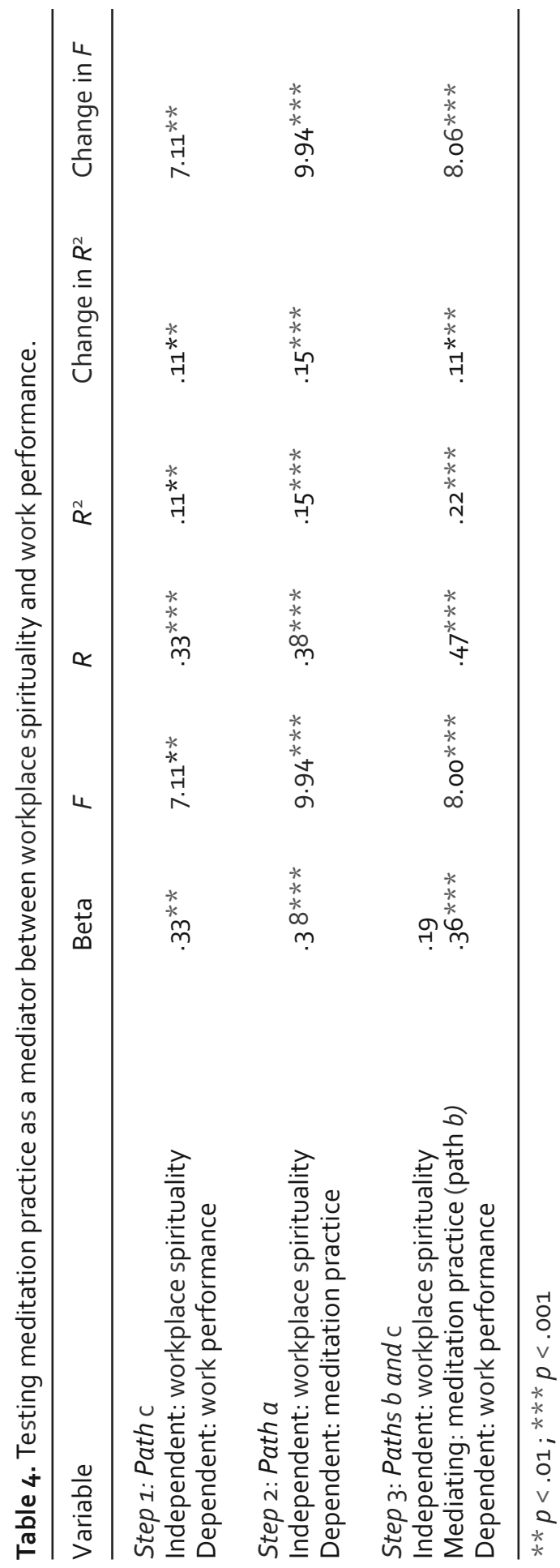


Table 5. Mean differences of work spirituality and work performance for experimental and comparison groups.

\begin{tabular}{|c|c|c|c|c|}
\hline & \multicolumn{2}{|c|}{$\begin{array}{l}\text { Experimental group } \\
\qquad(N=30)\end{array}$} & \multicolumn{2}{|c|}{$\begin{array}{l}\text { Comparison group } \\
\qquad(N=30)\end{array}$} \\
\hline & M & SD & M & SD \\
\hline \multicolumn{5}{|c|}{ Workplace spirituality scores } \\
\hline Pre & 3.94 & 0.42 & 3.88 & 0.40 \\
\hline Post & 3.82 & 0.35 & 3.78 & 0.43 \\
\hline \multicolumn{5}{|c|}{ Work performance scores } \\
\hline Post & 17.39 & 3.26 & 16.71 & 2.31 \\
\hline
\end{tabular}

Pre = time before attending training; Post = one month after attending training.

comparison groups indicate that the pre- and posttest spirituality scores are not different within either group, nor are the scores different between the groups (see Table 5). A repeated measures ANOVA test of spirituality scores for the experimental group at times 1, 2, and 3 indicates that spirituality scores do not significantly differ across time, $F(2,58)=1.25, P=.29$. These analyses suggest that the 8-day meditation training did not have an effect on spirituality scores. The data in Table 5 also show that while work performance scores are higher for the experimental group than the comparison group, these differences do not reach conventional levels of statistical significance $(p>.05)$. The data in Table 5 also suggest that insight meditation training is not related to work performance. While the work performance scores for individuals who completed the training are higher than scores for the comparison group $(17.39(\mathrm{SD}=3.26)$ vs. $16.71(\mathrm{SD}=2.31))$, this difference does not reach conventional levels of statistical significance $(t(58)=.95, p=.35)$ (see Table 5).

\section{Discussion}

One of the important tests in this research was an examination of the effects of a spiritual intervention: insight meditation training. The expectation was that the training would not only raise informants' sense of their own spiritual selves (i.e. spirituality scores would be higher after training), but also those who participated in the training might transfer to their jobs their newly learned ability to achieve insight and their work performance would improve. However, the data analyses reported cannot support those expectations.

It is possible, that the training did produce a "spirituality" effect but the measure could not show it. This might happen because of a "re-calibration" effect. That is, the informants might have had a "false sense" of their own spirituality which they discovered only as a consequence of the training. Additionally, meditation requires practice over a period of time longer than one month before they produce observable benefits. Indeed, the data analysis did show a link between (long-term) meditation practice and work outcomes. Also note that the 8-day training program may not be a 
sufficient length of time to produce an observable effect. Many researchers suggest an examination of long-term meditation practice (Frew 1974, Schmidt-Wilk 2003, Mackenzie et al. 2007).

While the short-term training in meditation technique did not seem to produce an effect in terms of a sense of spirituality or in terms of work performance, frequency of meditation practice does. Both studies demonstrated an effect for the regular practice of meditation. Study 1 showed that people who practiced meditation have higher workplace spirituality scores than those who practiced infrequently. Study 2 extended the examination of this relationship. Specifically, the regular practice of meditation partially mediates the positive relationship between workplace spirituality and work performance. In other words, practicing meditation strengthens the positive relationship between workplace spirituality and work performance. The more spiritual people are, the more they practice meditation and the more they practice meditation, the better they perform their work.

Finally, the research makes an important contribution to the study of spirituality at work because it provides empirical evidence of a significant, positive relationship between spirituality and actual work outcomes; not attitudes about work, not attitudes about commitment or job satisfaction, but work performance as it is measured by the organization. The overall connection between spirituality and work performance supports the findings reported by Duchon and Plowman (2005) and confirms a theoretical assumption that bringing spirituality to the workplace positively affects organizational outcomes (Neck and Milliman 1994, Biberman and Whitty 1997, Burack 1999, Cavanagh, 1999, Mitroff and Denton 1999, Cacioppe 2000, Pratt and Ashforth 2003, Jurkiewicz and Giacalone 2004, Kinjerski and Skrypnek 2004).

\section{Limitations}

Although this research attempted to examine the relationship among a spirituality intervention, workplace spirituality, and work performance, the study was conducted in Thailand with Thai subjects, many of whom, because of their Buddhist-centric culture, are conditioned to see meditation as something, if not "normal," at least "not unusual." Similarly, the idea of "spirituality" as a part of human experience that is separate from religion likely enjoys wider acceptance in the Thai culture than it would in North American culture. Nonetheless, because western research methods were used in an eastern (Thai) work context, it may be that the relationship between spirituality and work may is robust in any work context, although such speculation will, of course, require further examination.

\section{Managerial implication}

If the organization in which the research took place truly wants to achieve a workrelated outcome from the meditation training, it may have to modify the training in- 
tervention. For example, rather than allowing the participants to "figure things out," the training might include conversation and practice in how specifically to transfer meditation benefits to the workplace. It may not be intuitively obvious to training participants how an effort to achieve wisdom transfers to performing job tasks. Second, because an 8-day training may not be long enough to produce an effect, the company should consider regular follow- up programs where participants can be reengaged in meditation practice (Astin 1997). Meditation is not an easy thing to learn and a more long-term approach to the acquisition to meditation skills might be more effective.

It seems likely that people obtain the benefits of meditation, not quickly, but rather over a period of time. Effective meditation requires patience and persistence. Practice over a period of time enables the meditation practitioner to become more skilled at achieving the kind of mindfulness that leads to a sense of meaning in life, compassion, and transcendence. These cognitive effects are in addition to the stress reduction attributed to meditation that has been reported by others (Schmidt-Wilk et al. 1996, Biberman and Whitty 1997).

Nonetheless, the research reported here suggests that work performance is related to meaningful work, compassion, mindfulness, and transcendence and that attending to these issues can create a more productive work environment. Meaningful work provides employees an opportunity to realize their full potential as human beings. To promote meaningful work, organizations need to focus not only on designing jobs that provide meaning in a job characteristics sense (Hackman and Oldham 1976), but also addressing employee need at a deeper level (Ashar and Lane-Maher 2004, Duchon and Plowman 2005). This might mean paying attention to continuous learning and development, fully appreciating employee contributions, enhancing flexibility and autonomy, and promoting creativity and initiative (Kinjerski and Skrypnek 2004). Paying attention to work-life balance may also enhance meaningfulness at work (Pratt and Ashforth 2003) and contribute to a sense of greater compassion in the workplace. Larger structural and cultural issues such as organizational integrity, social responsibility, positive workplace culture and atmosphere, sense of community among members, and inspiring leadership can also play a role in enhancing workplace spirituality (Kinjerski and Skrypnek 2004).

Leadership is important in fostering a sense of transcendence. Pratt and Ashforth (2003) suggest that leaders can model behavioral integrity. Additionally, leaders can promote psychological safety by allowing employees to show themselves and demonstrate initiative and creativity without a fear of negative consequences to their career or status (Pratt and Ashforth 2003). The alignment of an employee's identity, value, and purpose, a result enabled by effective leadership, can foster transcendence (Pratt and Ashforth 2003). When leaders demonstrate congruence among the organization's vision, mission, goals, and practices, they will impact a sense of spirituality in the wider organization and contribute to a more effective work environment (Fry 2003, Fry et al. 2005, Fry et al. 2006, Fry and Slocum 2008, Fry and Cohen 2009, Fry and Kriger 2009). Indeed, the leader should insure that all parts of the organization 
are working together toward the same goals in support of corporate spiritual values.

As noted above, organizational factors such as culture, strategy, and HRM policies can enhance workplace spirituality, but the organization's leaders need to reinforce spirituality values. For example, McCulloch (2006) notes that workplace spirituality can be impaired when the employees' perception of organizational spirituality does not align with management's perception of organizational spirituality. Organizational leaders need to pay attention to the alignment of perceptions, and not take for granted that just because spirituality interventions like meditation training are available that the employees automatically understand such an opportunity indicating that spirituality is a core organization value and therefore important. Finally, even if organizational intentions and employee awareness are aligned, real effort needs to go into developing and maintaining a spirituality intervention such as training in insight meditation techniques. Insight meditation requires practice, and any organization seeking the benefits meditation promises will have to commit itself to a longterm view, and thus not expect a sudden, dramatic payoff.

\section{The Authors}

Pawinee Petchsawang is an assistant professor of human resource management, School of Business, University of the Thai Chamber of Commerce. She received her $\mathrm{PhD}$ in Business Administration from the University of Tennessee (Knoxville). She has written a book, Organizational Behavior (Bangkok: Ratthara, 2002), and published on human resource management and organizational behavior in management journals. She also has been a consultant for private and public sectors in the areas of human resource management in Thailand.

Dennis Duchon received his PhD in management from the University of Houston. He has published widely in management journals in the areas of leadership, decision-making, workplace spirituality, motivation, and complexity science.

\section{References}

Ashar, H. and Lane-Maher, M., 2004. Success and spirituality in the new business paradigm. Journal of Management Inquiry, 13(30), 249- 260.

Ashmos, D. P. and Duchon, D. , 2000. Spirituality at work: A conceptualization and measure. Journal of Management Inquiry, 9(2), 134-144.

Astin, J. A., 1997. Stress reduction through mindfulness meditation. Psychotherapy and Psychosomatics, 66, 97-106.

Baron, R. M. and Kenny, D. A., 1986. The moderator- mediator variable distinction in social psychological research: Conceptual, strategic, and statistical considerations. Journal of Personality and Social Psychology, 51(6), 11 73-1182.

Biberman, J. and Whitty, M., 1997. A postmodern spiritual future for work. Journal of Organizational Change, 10(2), 130-138. 
Birbili, M., 2000. Translating from one language to another. Social Research Update. Accessed April 11, 2008, from http:// sru.soc.surrey.ac.uk/SRU3I.html

Brown, K. W. and Ryan, R. M. , 2003. The benefits of being present: Mindfulness and its role in psychological well-being. Journal of Personality and Social Psychology, 84(4), 822-848.

Burack, E. H., 1999. Spirituality in the workplace. Journal of Organizational Change Management, 12(4), 280-291.

Cacioppe, R., 2000. Creating spirit at work: Re-visioning organization development and leadership - Part I. Leadership and Organization Development Journal, 21(2), 48-54.

Campbell, D. T. and Stanley, J. C., 1963. Experimental and Quasi-Experimental Designs for Research. Boston, MA: Houghton Mifflin.

Cavanagh, G. F., 1999. Spirituality for managers: Context and critique. Journal of Organizational Change Management, 12(3), 186-199.

Dehler, G. E. and Welsh, M. A., 2003. The experience of work: Spirituality and the new workplace. In: R. A. Giacalone and C. L. Jurkiewicz, eds. Handbook of Workplace Spirituality and Organizational Performance. Armonk, NY: M.E. Sharpe, 108-122.

Delaney, C., 2005. The spirituality scale: Development and psychometric testing of a holistic instrument to assess the human spiritual dimension. Journal of Holistic Nursing, 23(2), 145- 167.

Delgado, C., 2005. A discussion of the concept of spirituality. Nursing Science Quarterly, 18(2), 157-162.

Duchon, D. and Plowman, D. A., 2005. Nurturing the spirit at work: Impact on work unit performance. The Leadership Quarterly, 16, 807-833 .

Frew, D. R., 1974. Transcendental meditation and productivity. Academy of Management Journal, 17, 362-368.

Fry, L. W., 2003. Toward a theory of spiritual leadership. The Leadership Quarterly, 14, 693-727.

Fry, L. and Cohen, M., 2009. Spiritual leadership as a paradigm for organizational transformation and recovery from extended work hours cultures. Journal of Business Ethics, 84, 265-278.

Fry, L. and Kriger, M., 2009. Towards a theory of being-centered leadership: Multiple levels of being as context for effective leadership. Human Relations, 62(11), 1667-1696.

Fry, L. W., Matherly, L. L., and Vitucci, S., 2006. Spiritual leadership theory as a source for future theory, research, and recovery from workaholism. In: R. J. Burke, ed. Research Companion to Working Time and Work Addiction. Northampton, MA: Edward Elgar, 330-352.

Fry, L. W. and Slocum, J. W. Jr. , 2008. Maximizing the triple bottom line through spiritual leadership. Organizational Dynamics, 37(1), 86-96.

Fry, L. W., Vitucci, S., and Cedillo, M., 2005. Spiritual leadership and army transformation: Theory, measurement, and establishing a baseline. Leadership Quarterly, 16(5), 835-862.

George, R. G, Sorenson, G. J., and Bums, J. M. , 2004. Encyclopedia of Leadership. vol. 4. London: Sage.

Giacalone, R. A. and Jurkiewicz, C. L., 2003. Toward a science of workplace spirituality. In: R. A. Giacalone and C. L. Jurkiewicz, eds. Handbook of Workplace Spirituality and Organizational Performance. Armonk: M.E. Sharpe, 3-28.

Gull, G. A. and Doh, J., 2004. The "transmutation" of the organization. Journal of Management Inquiry, 13(2), 128-139.

Hackman, J. R. and Oldham, G. R., 1976. Motivation through the design of work: Test of a theory. Organizational Behavior and Human Performance, 16, 250-276. 
Hambleton, R. K., 2002. Adapting achievement tests into multiple languages for international assessments. In : A. C. Porter and A. Gamoran, eds. Methodological Advances in Cross-National Surveys of Educational Achievement. Washington, DC: National Academy Press, 58-73.

Harung, H.S., et al., 1996. Peak performance and higher states of consciousness: A study of world-class performers. Journal of Managerial Psychology, 11(4), 3- 23.

Hill, P. C. and Smith, G. S., 2003. Coming to terms with spirituality and religion in the workplace. In: R. A. Giacalone and C. L. Jurkiewicz, eds. Handbook of Workplace Spirituality and Organizational Performance. Armonk: M.E. Sharpe, 23 1-243.

Jurkiewicz, C. L. and Giacalone, R. A., 2004. A values framework for measuring the impact of workplace spirituality on organizational performance. Journal of Business Ethics, 49, 129-142.

Karakas, F., 2010. Spirituality and performance in organizations: A literature review. Journal of Business Ethics, 94, 89-106.

Kinjerski, V. M. and Skrypnek, B. J., 2004. Defining spirit at work: Finding common ground. Journal of Organizational Change, 17(1), 26-42.

Kinjerski, V. M. and Skrypnek, B. J., 2006. Measuring the intangible: Development of the spirit at work scale. The Sixty-Fifth Annual Meeting of the Academy of Management. Atlanta, GA. Accessed December 5, 2007, from http:// kaizensolutions.org.sawscale.pdf

Kolodinsky, R. W., Giacalone, R. A., and Jurkiewicz, C. L., 2008. Workplace values and outcomes: Exploring personal, organizational, and interactive workplace spirituality. Journal of Business Ethics, 81, 465-480.

Krahnke, K., Giacalone, R. A, and Jurkiewicz, C. L., 2003. Point-counterpoint: Measuring workplace spirituality. Journal of Organizational Change, 16(4), 396-405.

Krishnakumar, S. and Neck, C. P., 2002. The "what", "why" and "how" of spirituality in the workplace. Journal of Managerial Psychology, 17(3), 153-164.

Laabs, J. J. (1995, September). Balancing spirituality and work. Personnel Journal, 74(9), 60-76.

Luthans, F., Youssef, C. M., and Avolio, B. J., 2007. Psychological Capital: Developing the Human Competitive Edge. New York: Oxford University Press.

Mackenzie, M. J., et al., 2007. A qualitative study of self-perceived effects of mindfulness- based stress reduction (MBSR) in a psychosocial oncology setting. Stress and Health, 23, 59-69.

Marques, J., 2010. Toward greater consciousness in the 21st century workplace: How Buddhist practices fit in. Journal of Business Ethics, 92, 211-225.

Maxwell, B., 1996. Translation and cultural adaptation of the survey instruments. In: M. O. Martin and D. L. Kelly, eds. Third International Mathematics and Science Study (TIMSS) Technical Report, Design and Development. Vol. I. Boston, MA: Boston College, 8.1-8.9.

McCulloch, A. S., 2006. Spirituality in business: An exploration into three exemplar for-profit organizations, using qualitative and quantitative measures. Unpublished doctoral dissertation. Institute of Transpersonal Psychology, Palo Alto, CA.

McCollum, B., 1999. Leadership development and self-development: An empirical study. Career Development International, 4(3), 149-154.

Milliman, J., Czaplewski, A. J., and Ferguson, J., 2003. Workplace spirituality and employee work attitudes: An exploratory empirical assessment. Journal of Organizational Change Management, 16(4), 426-447.

Mitroff, I. I. and Denton, E. A., 1999. A Spiritual Audit of Corporate America. San Francisco, CA: Jossey-Bass. 
Neck, C. P. and Milliman, J. F., 1994. Thought self-leadership: Finding spiritual fulfillment in organizational life. Journal of Managerial Psychology, 6, 9-16.

Pawar, B. S., 2008. Two approaches to workplace spirituality facilitation: A comparison and implications. Leadership \& Organization Development Journal, 29(6), 544-567.

Pawar, B. S., 2009. Workplace spirituality facilitation: A comprehensive model. Journal of Business Ethics, 90, 375-386.

Payutto, P. A. , 2002. Samadhi in Buddhism. 2nd ed. Bangkok: Buddha Dhamma Foundation.

Petchsawang, P. and Duchon, D., 2008. Measuring workplace spirituality in an Asian context. Human Resource Development International, 12(4), 459-468.

Rajaprommajarn, P., 2004. Path to Nibbana, complete edition. Chiengmai: Changpeuk.

Pratt, M. G. and Ashforth, B. E., 2003. Fostering meaningfulness in working and at work. In: K. S. Cameron, J. E. Dutton, and R. E. Quinn, eds. Positive Organizational Scholarship: Foundations of a New Discipline. San Francisco, CA: Berrett-Koehler, 309-327.

Schmidt-Wilk, J., 2003. TQM in Europe: A case study TQM and the transcendental meditation program in a Swedish top management team. The TQM Magazine, 15(4), 219-229.

Schmidt-Wilk, J., Alexander, C. N., and Swanson, G. C., 1996. Developing consciousness in organizations: The transcendental meditation program in business. Journal of Business and Psychology, 10(4), 429-444.

Schroevers, M. J. and Brandsma, R., 2010. Is learning mindfulness associated with improved affect after mindfulness-based cognitive therapy? British Journal of Psychology, 101, 95-107.

Tepper, B. J., 2003. Organizational citizenship behavior and the spiritual employee. In: R. A. Giacalone and C. L. Jurkiewicz, eds. Handbook of Workplace Spirituality and Organizational Performance. Armonk: M.E. Sharpe, 181-190.

Thompson, B. L. and Waltz, J., 2007. Everyday mindfulness and mindfulness meditation: Overlapping constructs or not? Personality and Individual Difference, 43, 1875-1885.

Tischler, L., Biberman, J., and McKeage, R., 2002. Link emotional intelligence, spirituality and workplace performance: Definitions, model and ideas for research. Journal of Managerial Psychology, 17(3), 203- 218.

Weick, K. E. and Putnam, T., 2006. Organizing for mindfulness: Eastern wisdom and Western knowledge. Journal of Management Inquiry, 15(3), 275-287.

Weick, K. E. and Sutcliffe, K. M., 2006. Mindfulness and the quality of organizational attention. Organization Science, 17(4), 514-524. 